\title{
Experimental comparison of PVD, CVD and CERAMIC tool inserts in turning of hardened EN 19/AISI 4140 for optimization of surface roughness and material removal rate
}

\author{
Santosh Kumar A. Lawate ${ }^{1}$, Abhijeet S. Suryawanshi ${ }^{2}$, Aditya S. Durgavale ${ }^{3}$, Sourabh V Patil ${ }^{4}$ \\ Assistant Professor, Mechanical Engineering Department, DACOE Karad ${ }^{1,2}$ \\ UG Student, Mechanical Engineering Department, DACOE Karad ${ }^{3,4}$
}

\begin{abstract}
The literature study on optimization of surface roughness states that there are many parameters that affect optimum surface roughness to be reached after machining. It is primarily seen that many researchers carried out their studies on various cutting parameters (viz. speed, feed, depth of cut) as their input parameters and concluded that Feed is important parameter ${ }^{[5][6][8][9][12][14]}$ for optimizing surface roughness and also some researches made clear that depth of cut ${ }^{[2][3][8][10]}$ affects the response of surface roughness.Researches were also carried out by studying the effect of input parameters like changing the tool inserts and also by changing nose radius of various inserts ${ }^{[6][13]}$. Experiments were also carried out by varying the quantity of lubrication ${ }^{[15]}$ The optimum value of surface roughness was reached by using taguchi ${ }^{[1][3][5][8][9][12]}$ method and response surface methodology ${ }^{[6][8][13]}$ The research carried out on EN 19 / AISI 4140 for optimum surface roughness was studied by taking cutting parameters like speed, feed and depth of cut ,states that the depth of cut is most significant parameter $^{[2][3][8][10]}$. No research states appropriate tool insert with appropriate nose radius at the optimized depth of cut for EN 19 / AISI 4140 at hardness of 35 HRC
\end{abstract}

Keywords: Taguchi, surface roughness, turning, optimization.

\section{INTRODUCTION}

In manufacturing field, turning operation is a very common material removal technique. Researches on this topic take into account several aspects, such as: geometrical and metallurgical characteristics of the cutting tool, workpiece material influence on the process and process parameters. The interaction of all these factors during a cutting operation causes a series of effects on output parameters that influence the process

Significant advances have been seen in cutting tools and machine tools in recent years. Cutting parameters may be specified according to hardness of materials and roughness of the surface of a work piece. The advantages in machining materials with higher hardness are decreasing machining costs, saving time, improving surface quality, and eliminating of deformities in parts caused by temperature

Surface roughness is one of the most important requirements in machining process, as it is considered an index of product quality. It measures the finer irregularities of the surface texture. Achieving the desired surface quality is critical for the functional behaviour of a part. Surface roughness influences the performance of mechanical parts and their production costs because it affects factors, such as friction, ease of holding lubricant, electrical and thermal conductivity, geometric tolerances and more. The ability of a manufacturing operation to produce a desired surface roughness depends on various parameters. The factors that influence surface roughness are machining parameters, tool and work piece material properties and cutting conditions. For example, in turning operation the surface roughness depends on cutting speed, feed rate, depth of cut, tool nose radius, lubrication of the cutting tool, machine vibrations, tool wear and on the mechanical and other properties of the material being machined. Even small changes in any of the mentioned factors may have a significant effect on the produced surface. Therefore, it is important for the researchers to model and quantify the relationship between roughness and the parameters affecting its value.

\section{LITERATURE REVIEW}

\section{Meenu Sahu and Komesh Sahir ${ }^{[1]}$}

This paper presents an optimization method of the cutting parameters (cutting speed, depth of cut and feed) in dry turning of AISI D2 steel to achieve minimum tool wear, low workpiece surface temperature and maximum material removal rate (MRR). The experimental layout was designed based on the Taguchi's L9(34) Orthogonal array technique and analysis of variance (ANOVA) was performed to identify the effect of the cutting parameters on the response variables. The results showed that depth of cut and cutting speed are the most important parameter 


\section{IARJSET}

International Advanced Research Journal in Science, Engineering and Technology

National Conference on Design, Manufacturing, Energy \& Thermal Engineering (NCDMETE-2017)

AGTI's Dr. Daulatrao Aher College Engineering, Vidyanagar Extension, Karad

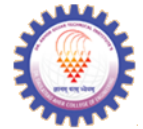

Vol. 4, Special Issue 1, January 2017

influencing the tool wear. The minimum tool wear was found approach has been adopted. The results have indicated that it at cutting speed of $150 \mathrm{~m} / \mathrm{min}$, depth of cut of $0.5 \mathrm{~mm}$ and is feed rate which has significant influence both on cutting feed of $0.25 \mathrm{~mm} / \mathrm{rev}$. Similarly low w/p surface temperature force as well as surface roughness. Depth of cut has a was obtained at cutting speed of $150 \mathrm{~m} / \mathrm{min}$, depth of cut of significant influence on cutting force, but has an insignificant $0.5 \mathrm{~mm}$ and feed of $0.25 \mathrm{~mm} / \mathrm{rev}$. Whereas, at cutting speed influence on surface roughness.

of $250 \mathrm{~m} / \mathrm{min}$, depth of cut $1.00 \mathrm{~mm}$ and feed of 0.25 $\mathrm{mm} / \mathrm{rev}$, the maximum MRR was obtained.

\section{Ashvin J. Makadia, J.I. Nanavati ${ }^{[6]}$}

Ashish Kabra, Amit Agarwal, Vikas Agarwal Sanjay Goyal, Ajay Bangar ${ }^{[2]}$

In this paper, application of RSM on the AISI 410 steel is carried out for turning operation. A quadratic model has been developed for surface roughness $(\mathrm{Ra})$ to investigate the This paper outlines an experimental study to optimize and study the effects of process parameters in CNC turning on Surface roughness, feed and radial forces of EN19/AISI4140 (medium carbon steel) work material in dry environment conditions. The orthogonal array, signal to noise ratio and analysis of variance are employed to study the performance characteristics in CNC turning operation. Three machining parameters are chosen as process parameters: Cutting Speed, Feed rate and Depth of cut. The experimentation plan is designed using Taguchi's L9 Orthogonal Array (OA)

\section{Jakhale Prashant P, Jadhav B. R. $^{[3]}$}

In this paper attempt has been made to investigate the effect of cutting parameters (cutting speed, feed rate, depth of cut) and insert geometry(CNMG and DNMG type insert) on surface roughness in the high turning of alloy steel. The experiments have been conducted using L9 orthogonal array in a TACCHI lathe $\mathrm{CNC}$ turning machine. Turning process carried out on the high alloy steel(280 BHN).The optimum cutting condition was determined by using the statistical methods of signal-to-noise $(\mathrm{S} / \mathrm{N})$ ratio and the effect of cutting parameters and insert type on surface roughness were evaluated by the analysis of variance (ANOVA).

Biermann, D., Hartmann, H., Terwey, I, Merkel, C., Kehl, D. ${ }^{[4]}$

In this paper, turning of the bainitic steel $20 \mathrm{MnCrMo} 7+\mathrm{BY}$ in comparison to the quenched and tempered steels 42CrMo4+QT and 50CrMo4+QT is analysed. The experiments conducted have shown that high strength bainitic steels can be machined. It must be concluded however, that the possible material removal rate is significantly lower than for machining the often used quenched and tempered steel 42CrMo4+QT due to the higher hardness of bainitic steels. The same result applies for turning the high-strength quenched and tempered steel 50CrMo4+QT whose mechanical properties are comparable to the ones of the bainitic steel.

\section{Dr. C. J. Rao, Dr. D. Nageswara Rao, P. Srihari ${ }^{[5]}$}

influence of machining parameters. The results are as follows:

(1) For the surface roughness, the feed rate is the main influencing factor on the roughness, followed by the tool nose radius and cutting speed. Depths of cut haveno significant effect on the surface roughness.

(2) It can be seen that interaction between most factors has no significant effect except feed rate and tool nose radius which have the highest influence.

(3) 3D surface counter plots are useful in determining the optimum condition to obtain particular values of surface roughness.

(4) Response surface optimisation shows that the optimal combination of machining parameters are (255.75 $\mathrm{m} / \mathrm{min}, 0.1 \mathrm{~mm} / \mathrm{rev}, 0.3 \mathrm{~mm}, 1.2 \mathrm{~mm}$ ) for cutting speed, feed rate, depth of cut and tool nose radius respectively.

(5) Verification experiments carried out show that the empirical models developed can be used for turning of AISI-410 steel within $6 \%$ error.

\section{M.Arft, F.Klocke ${ }^{[7]}$}

In the presented study the difficult to machine material Austempered Ductile Iron (ADI) was investigated. First, the relevant machinability aspects and the material properties were presented. The alternating tool load, especially the peaks of the cutting force, have been identified as responsible for both tool breakage and increased wear due to a relative movement between insert and work-piece. A 3D-FEM simulation model of the external longitudinal turning process was developed to investigate the effects of a variation in tool geometry on the alternating tool load. By using the presented model, an optimized insert geometry with an increased tool life was developed, which was validated in empirical cutting tests using the optimized tool geometry. Tool life was increased by $70 \%$ in dry turning and by $100 \%$ in wet conditions. Furthermore, no tool breakage was observed by using the optimized tool.

Mohamed Elbah Mohamed Athmane Yallese Hamdi Aouici, Tarek Mabrouki Jean-Fran?ois Rigal ${ }^{[8]}$

This research reports the significance of influence of speed, This study considers the comparison between the surface feed and depth of cut on cutting force and surface roughness roughness criteria ( $\mathrm{Ra}, \mathrm{Rz}$ and $\mathrm{Rt}$ ) of the wiper inserts with while working with tool made of ceramic with an conventional inserts during hard turning of AISI 4140 A12O3+T1C matrix (KY1615)and the work material of hardened steel (60 HRQ.The planning of experiments was AISI 1050 steel (hardness of $484 \mathrm{HV}$ ). Experiments were based on Taguchi's L27 orthogonal array. The response conducted using Johnford TC35 Industrial type of CNC lathe. surface methodology (RSM) and analysis of variance Taguchi method (L27 design with 3 levels and 3 factors) was (ANOVA) were used to check the validity of quadratic used for the experiments. Analysis of variance with adjusted regression model and to determine the significant parameter 
IAR JSET

International Advanced Research Journal in Science, Engineering and Technology

National Conference on Design, Manufacturing, Energy \& Thermal Engineering (NCDMETE-2017)

AGTI's Dr. Daulatrao Aher College Engineering, Vidyanagar Extension, Karad

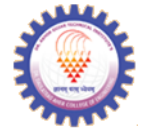

Vol. 4, Special Issue 1, January 2017

affecting the surface roughness. The statistical analysis reveals feed rate-cutting speed and depth of cut-cutting speed that the feed rate and depth of cut have significant effects in appear to be important reducing the surface roughness.

\section{Mustafa Gunay, Emre Yucel ${ }^{[9]}$}

This paper focuses on optimizing the cutting conditions for the average surface roughness $(\mathrm{Ra})$ obtained in machining of high-alloy white cast iron (Ni-Hard) at two different hardness levels (50 HRC and 62 HRC). Machining experiments were performed at the $\mathrm{CNC}$ lathe using ceramic and cubic boron nitride $(\mathrm{CBN})$ cutting tools on Ni-Hard materials. Cutting speed, feed rate and depth of cut were chosen as the cutting parameters. Taguchi LI 8 orthogonal array was used to design of experiment. Optimal cutting conditions was determined using the signal-to-noise $(\mathrm{S} / \mathrm{N})$ ratio which was calculated for $\mathrm{Ra}$ according to the "thesmaller-the-better" approach.

\section{V.Sivaraman, S.Sankaran, L.Vijayaraghavan ${ }^{[10]}$}

1. During machining multiphase microalloyed steel the cutting forces decreases as the cutting speed increases. The cutting forces are increased as the feed and depth of cut are increased for various cutting conditions.

2. The ANOVA for means shows that feed and depth of cut are the significant parameters which influence the cutting force than cutting speed.

3. The optimum parameter to machine the multiphase microalloyed steel are cutting velocity $80 \mathrm{~m} / \mathrm{min}$, feed $0.05 \mathrm{~mm} / \mathrm{rev}$ and depth of cut $0.1 \mathrm{~mm}$.

A.P.Paiva, P.H.Campos, J.R.Ferreira, L.G.D.Lopes, E.J. Paiva, P.P. Balestrassi ${ }^{[11]}$

This paper presents an experimental study of AISI 52100 hardened steel turned with wiper mixed ceramic (A12O3+TiC) inserts coated with TiN, using Multivariate Robust Parameter Design (MRPD). The main characteristic of this new optimization approach consists of considering both controllable (xi) and noise (zi) variables of the hard turning process to find out the parameter levels which minimize the distance of each response (yi) from its respective targets (Ti) while keeps each variance caused by the noise variables as low as possible.

\section{Ilhan Asilturk, Harun Akkus ${ }^{[12]}$}

This study focuses on optimizing turning parameters bused on the Taguehi method to minimize surface roughness ( $\mathrm{Ra}$ and $\mathrm{Rz}$ ). Experiments have been conducted using the L9 orthogonal array in a CNC turning machine. Dry turning tests arc carried out on hardened AISI 4140 (51 HRC) with coated carbide cutting tools, Each experiment is repeated three times and each test uses a new cutting insert to ensure accurate readings of the surface roughness. The statistical methods of signal to noise ratio (SNR) and the analysis of variance (ANOVA) are applied to investigate effects of cutting speed, feed rate and depth of cut on surface roughness. Results of this study indicate that the feed rate has the most significant effect on $\mathrm{Ra}$ and Rz. In addition, the effects of two factor interactions of the

\section{Suleyman Neseli, Suleyman Yaldiz Erol Turkes ${ }^{[13]}$}

This investigation focuses on the influence of tool geometry on the surface finish obtained in turning of AISI 1040 steel. In order to find out the effect of tool geometry parameters on the surface roughness during turning, response surface methodology (RSM) was used and a prediction model was developed related to average surface roughness (Ra) using experimental data. The results indicated that the tool nose radius was the dominant factor on the surface roughness

Hamdi Aouici, Mohamed Athmane Yallese, Brahim Fnides, Kamel Chaoui and Tarek Mabrouki ${ }^{[14]}$

This paper, aims to investigate, under turning conditions of hardened AISI HIl (X38CrMoV5-1), the effects of cutting parameters on flank wear (VB) and surface roughness ( $\mathrm{Ra}$ ) using $\mathrm{CBN}$ tool. The machining experiments are conducted based on the response surface methodology (RSM). Combined effects of three cutting parameters, namely cutting speed, feed rate and cutting time on the two performance outputs (i.e. $\mathrm{VB}$ and $\mathrm{Ra}$ ), are explored employing the analysis of variance (ANOVA). Optimal cutting conditions for each performance level are established and the relationship between the variables and the technological parameters is determined using a quadratic regression model. The results show that the flank wear is influenced principally by the cutting time and in the second level by the cutting speed. Also, it is that indicated that the feed rate is the dominant factor affecting workpiece surface roughness.

\section{N.R. Dhar, M. Kamruzzaman, Mahiuddin Ahmed ${ }^{[15]}$}

This paper deals with experimental investigation on the role of MQL on tool wear and surface roughness in turning AISI-4340 steel at industrial speed-feed combination by uncoatcd carbide insert. The encouraging results include significant reduction in tool wear rule and surface roughness by MQL mainly through reduction in the cutting /.one temperature and favorable change in the chip-tool and worktool interaction.

\section{III.GAPS IN LITERATURE SURVEY}

The literature study on optimization of surface roughness states that there are many parameters that affect optimum surface roughness to be reached after machining. It is primarily seen that many researchers carried out their studies on various cutting parameters (viz. speed, feed, depth of cut) as their input parameters and concluded that Feed is important parameter ${ }^{[5][6][8][9][12][14]}$ for optimizing surface roughness and also some researches made clear that depth of cut $^{[2][3][8][10]}$ affects the response of surface roughness. Researches were also carried out by studying the effect of input parameters like changing the tool inserts and also by changing nose radius of various inserts ${ }^{[6][13]}$. Experiments were also carried out by varying the quantity of lubrication ${ }^{[15]}$ 


\section{IARJSET}

The optimum value of surface roughness was reached by using taguchi ${ }^{[1][3][5][8][9][12]}$ method and response surface methodology ${ }^{[6][8][13]}$ The research carried out on EN 19 / AISI 4140 for optimum surface roughness was studied by taking cutting parameters like speed, feed and depth of cut ,states that the depth of cut is most significant parameter $r^{[2][3][8][10]}$. No research states appropriate tool insert with appropriate nose radius at the optimized depth of cut for EN 19 / AISI 4140 at hardness of $35 \mathrm{HRC}$.

\section{III.CONCLUDED OBJECTIVES}

I. To find best possible tool insert to be used for the required turning of Tin 19 for getting optimum surface roughness

II. To generate statistical data for various tool inserts which can be used for the required turning of Kn 19 so that it is available to various manufacturing industries

III Performance analysis of selected tool inserts by taking real lime actual trials on available CNC lathe machine

IV. To find the optimized input parameters from selected levels for tolerable response parameters.

V. To investigate for the further scope of research for different process parameters in turning in future.

\section{REFERENCES}

1. Meenu Sahu and Komesh Sahu "Optimization of Cutting Parameters on Tool Wear, Workpiece Surface Temperature and Material Removal Rate in Turning of AISI D2 Steel" International Journal of Advanced Mechanical Engineering. ISSN 2250-3234 Volume 4, Number 3 (2014), pp. 291-298

2. Ashish Kabra, Amit Agarwal, Vikas Agarwal Sanjay Goyal, Ajay Bangar "Parametric Optimization \& Modeling for Surface Roughness, Feed and Radial Force of EN-19/ANSI-4140 Steel in CNC Turning Using Taguehi and Regression Analysis Method". International Journal of Engineering Research and Applications (IJERA) ISSN; 2248-9622 www.ijeru.com Vol. 3, Issue1, January-February 2013, pp.1537-1544

3. Jakhale Prashant P, Jadhav B. R, "optimization of surface roughness of alloy steel by changing operational parameters and insert geometry in the turning process". international journal of advanced engineering research and studies e-issn2249-8974

4. Bicrmann, D., Hartmann, H., Tcrwey, I, Merkel, C., Kehl, D, "Turning of high- strength bainitic and quenched and tempered steels". Procedia CIRP 7( 2013 )276-28

5. Dr. C. J. Rao, Dr. D. Nageswara Rao, P. Srihari. "Influence of cutting parameters on cutting force and surface finish in turning operation". Procedia Engineering 64 (2013 ) 1405 - 1415

6. Ashvin J. Makadia, J.I. Nanavati. "Optimisation of machining parameters for turning operations based on response surface methodology". Measurement 46 (2013) 1521-1529

7. M.Arft , F.Klocke . "High Performance Turning of Austempered Ductile Iron(ADI) with adapted Cutting Inserts". Procedia CIRP ( 2013 ) 129 - 134

8. Mohamed Elbah, Mohamed Athmane Yallese, Hamdi Aouici, Tarek Mabrouki Jean-Fran9ois Rigal . " Comparative assessment of wiper and conventional ceramic tools on surface roughness in hard turning AiSl 4140 steel”. Measurement 46 (2013) 3041-3056

9. Mustafa Gunay, Emre Yucel. “Application of Taguchi method for determining optimum surface roughness in ruining of highalloy white cast iron". Measurement 46 (2013) 913-919

10. V.Sivaraman, S.Sankaran, L.Vijayaraghuvan. "The Effect of Cutting Parameters on Cutting Force During Turning Multiphase Microalloycd Steel”. Procedia CIRP4(2Q12) 157160
A.P. Paiva, P.H. Campos, J.R. Ferreira, L.G.D. Lopes, EJ. Paiva, P.P.Balestrassi . "A multivariate robust parameter design approach for optimization of AISI 52100 hardened steel turning with wiper mixed ceramic tool". Int. Journal of Refractory Metals and Hard Materials 30 (2012) 152-163

12. Ilhan Asilrurk, Harun Akkus "Determining the effect of cutting parameters on surface roughness in hard turning using the Taguchi method". Measurement 44(2011) 1697-1704

13. Suleyman Neseli, Suleyman Yaldiz, Erol Turkes "Optimization of tool geometry parameters for turning operations based on the response surface methodology". Measurement 44 (2011) 580-587

14. Hamdi Aouici, Mohamed Athmane Yallese, Hrahim Fnides, Kamel Chaoui and Tarek Mabrouki. "Modeling and optimization of hard turning of X38CrMoV5-1 steel with CBN tool Machining parameters effects on flank wear and surface rou\$rness". Journal of Mechanical Science and Technology 25(11) (2011) 2843-2851 www.springerlink.com/content/J738494xDOI10.1007/s12206-0110807-z

15. N,R. Dhar, M, Kamruzzaman, Muhiuddin Ahmed. "Effect of minimum quantity lubrication (MQL) oa tool wear and surface roughness in turning AISI-4340 steel". Journal of Materials Processing Technology J 72 (2006) 299-304 